\title{
Gross Ascites as a First Manifestation of Primary Hypothyroidism due to Post-treatment of Radioiodine Therapy for Graves' disease
}

\author{
Haruka Sasaki*, Seiichiro Matsumoto, Hiroshi Shijyo, Masanori Shimizu, \\ Keiji Tohara, Nobutaka Tsutsu** and Makoto OKumura
}

\begin{abstract}
We report herein a case with myxedema (primary hypothyroidism) associated with marked ascites that was found during the course of examination for a suspected decompensated state of liver cirrhosis or malignant disease. Aspirated ascitic fluid was found to have the characteristics of the exudate. Thyroid hormone replacement resulted in rapid clinical improvement with resolution of the ascites. This case is an unusual association of hypothyroidism as a cause of ascites. In all cases with ascites of unknown etiology, the differential diagnosis requires consideration of myxedema.
\end{abstract}

(Internal Medicine 31: 256-259, 1992)

Key words: ascites, myxedema, myxedematous ascites, thyroxine replacement

\section{Introduction}

The clinical onset of hypothyroidism is frequently insidious, with signs which are subtle or suggestive of other diseases. Ascites is not a widely recognized aspect of hypothyroidism (1-3). Sometimes less common manifestations dominate the clinical picture and the diagnosis may be missed.

Here, a case of myxedema with gross ascites as the major clinical manifestation is reported.

\section{Case Report}

A 60-year-old man was referred to Fukuoka University hospital in September 1988 because of abdominal distention and ascites of several months duration. Three years before, he was diagnosed as having liver dysfunction, and has since been receiving treatment of some medications. Prior to admission, his private physician prescribed furosemide and spironolactone for several weeks, but the ascites did not respond to these medications. A malignant disease with ascites was suspected.

On physical examination, blood pressure was 128/ $96 \mathrm{mmHg}$, pulse rate was $60 / \mathrm{min}$, respiratory rate was $18 / \mathrm{min}$, and the body temperature was $36^{\circ} \mathrm{C}$. The abdo- men was distended with marked ascitic fluid, and there was also slight pretibial edema. Neither the liver nor spleen were palpable. The thyroid gland was also not palpable on careful examination. There was no evidence of congestive heart failure or renal disease. The Achilles tendon reflexes were considered normal. The results of laboratory studies were hematocrit, $29.8 \%$; leukocyte count, $4,700 / \mathrm{mm}^{3}$ with a normal differentiation and platelet count, $18.5 / \mathrm{mm}^{3}$. There was no proteinuria. The test for $\mathrm{C}$-reactive protein was negative and the erythrocyte sedimentation rate was $10 \mathrm{~mm} / \mathrm{h}$. His heart size was slightly enlarged (CTR 54\%), and a small volume of left pleural effusion was found on chest radiography. The electrocardiogram showed complete right branch block. The total serum protein was $7.2 \mathrm{~g} / \mathrm{dl}$, albumin $3.9 \mathrm{~g} / \mathrm{dl}$ and globulin $1.2 \mathrm{~g} / \mathrm{dl}$. Serological tests such as antinuclear factor, rheumatoid factor and LE cell preparation were all negative. Alkaline phosphatase was $105 \mathrm{IU} / 1$ (N, 75-290); glutamic-oxalacetic transaminase (GOT) $42-114$ IU/l $(\mathrm{N},<40)$, glutamic pyruvic transaminase (GPT) 30-83 IU/1 $(\mathrm{N},<40)$, serum cholineesterase (ChE) 124IU/1 (N, 165-306), thymol turbidity test (TTT) 1.6 Kunkel $\mathrm{U}(\mathrm{N},<5)$ and zinc sulfate turbidity test (ZTT) 9.5 Kunkel U/1 (N, 4-12). Total serum bilirubin was $0.4 \mathrm{mg} / \mathrm{dl}$, prothrombin time was $65 \%(\mathrm{~N}$,

From The First Department of Internal Medicine, School of Medicine, Fukuoka University, Fukuoka, *Institute of Health Science, Kyushu University, Fukuoka, ** Fukuoka Red-Cross Hospital, Fukuoka

Received for publication January 30, 1991; Accepted for publication July 9, 1991

Reprint requests should be addressed to Haruka Sasaki, MD, Institute of Health Science, Kyushu University, 6-1 Kasuga-Koen, Kasuga 816, Japan 
$70-140$ ). The retention of indocyanine green (ICG) of $15 \min$ was $12.5 \%(\mathrm{~N},<10)$ and $\mathrm{K}$-value 0.149 . Lactate dehydrogenase (LDH) and creatine phosphokinase (CPK) were slightly raised at $667 \mathrm{IU} / \mathrm{l}(\mathrm{N}, 200-520)$ and $291 \mathrm{IU} / 1$ (N, 23-170), respectively. The serum cholesterol concentration was $214 \mathrm{mg} / \mathrm{dl}$. Creatinine clearance and phenolsulfonphthalein (PSP) test were all normal. The $99 \mathrm{~m}$-technetium (Tc) phytate liver scan showed an abnormal uptake suggesting either cirrhosis or chronic hepatitis and there was slight splenomegaly (Fig. 1). Abdominal echogram and computed tomography revealed gross ascites with no abnormality in the liver and a smooth surface (Fig. 2A and C). 67-Ga citrate tumor imaging showed no abnormal uptake. Tumor markers such as alpha fetoprotein (AFP), carcinoembryonic antigen (CEA) and colorectal carcinoma antigens (CA19-9) were all within the normal limits. Hepatitis B surface antigen and hepatitis $C$ virus antibody was negative. A barium enema and gastroscopy revealed no abnormalities. A diagnostic abdominal paracentesis yielded trubing yellow and transparent ascitic fluid with a specific gravity of 1,029 , protein concentration $4.0 \mathrm{~g} / \mathrm{dl}$, and sugar $106 \mathrm{mg} / \mathrm{dl}$. No malignant cells were found. Fungal, acid-fast and routine bacterial cultures were negative. Basal plasma aldosterone and urinary aldosterone excretion were $12.5 \mathrm{ng} / \mathrm{dl}$ (supine normal, 3.517.5 ) and $1.5 \mu \mathrm{g} /$ day (normal, $0.5-17.5$ ), respectively.

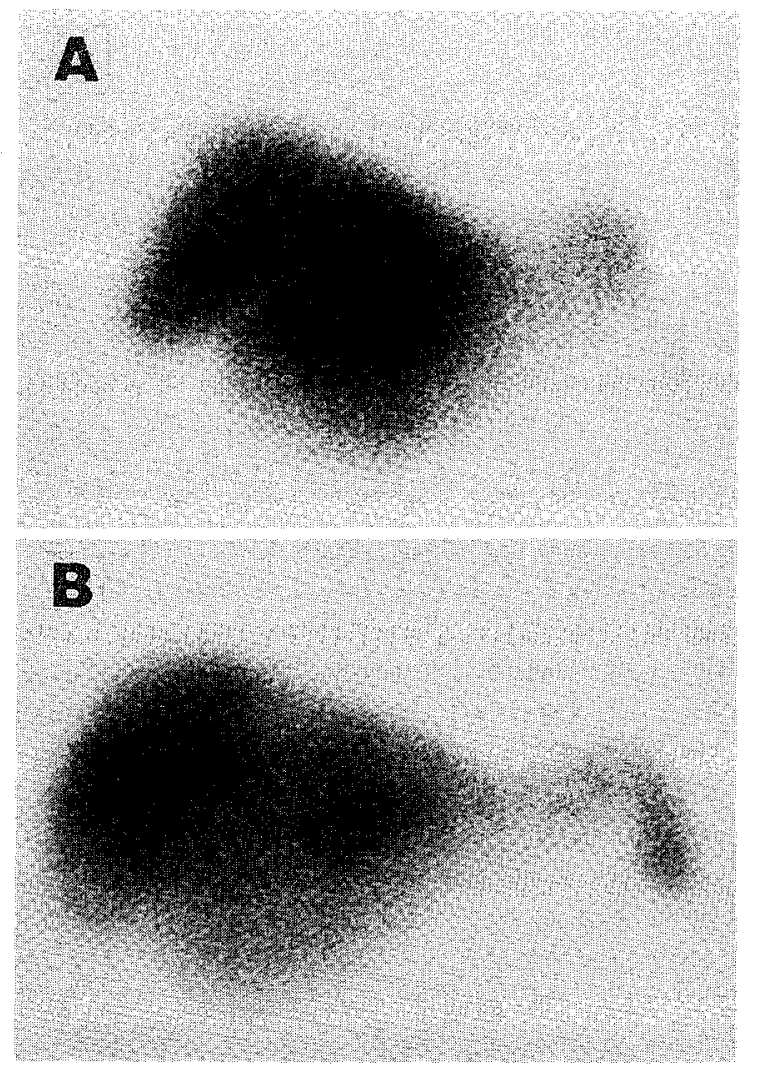

Fig. 1. $99 \mathrm{~m}-\mathrm{Tc}$ liver scintigram before (A) and after (B) resolution of ascites during $L$-thyroxine replacement
Both diuretics (furosemide $20 \mathrm{mg}$ and spironolactone $100 \mathrm{mg} /$ day) and a sodium restricted diet were prescribed again, but no response was observed.

Based on the patient's past history, he had been diagnosed elsewhere at the age of $40(1968)$ as having hyperthyroidism due to Graves' disease because of diffuse goiter, nervousness and excessive sweating. This diagnosis was based on the triiodotyronine (T3) resin sponge uptake of $52.0 \%(\mathrm{~N}, 25-30)$, and 131-radioiodine (131I) thyroid uptake of $75.4 \% / 24 \mathrm{~h}(\mathrm{~N}, 10-35)$ (Fig. 3A). He had been treated with 131-I therapy $(10 \mathrm{mCi})$. From that time, he had not been followed for this disease by any physician. Therefore, we suspected primary hypothyroidism due to post-treatment of radioiodine therapy. This diagnosis was confirmed by the following endocrine examinations; serum total thyroxine (T4) $1.0 \mu \mathrm{g} / \mathrm{dl}(\mathrm{N}$, 4.6-12.6), total T3 $30 \mathrm{ng} / \mathrm{dl}(\mathrm{N}, 80-180)$, free T4 less than $0.2 \mathrm{ng} / \mathrm{dl}(\mathrm{N}, 0.85-2.15)$, free T3 less than $1.0 \mathrm{pg} / \mathrm{ml}$
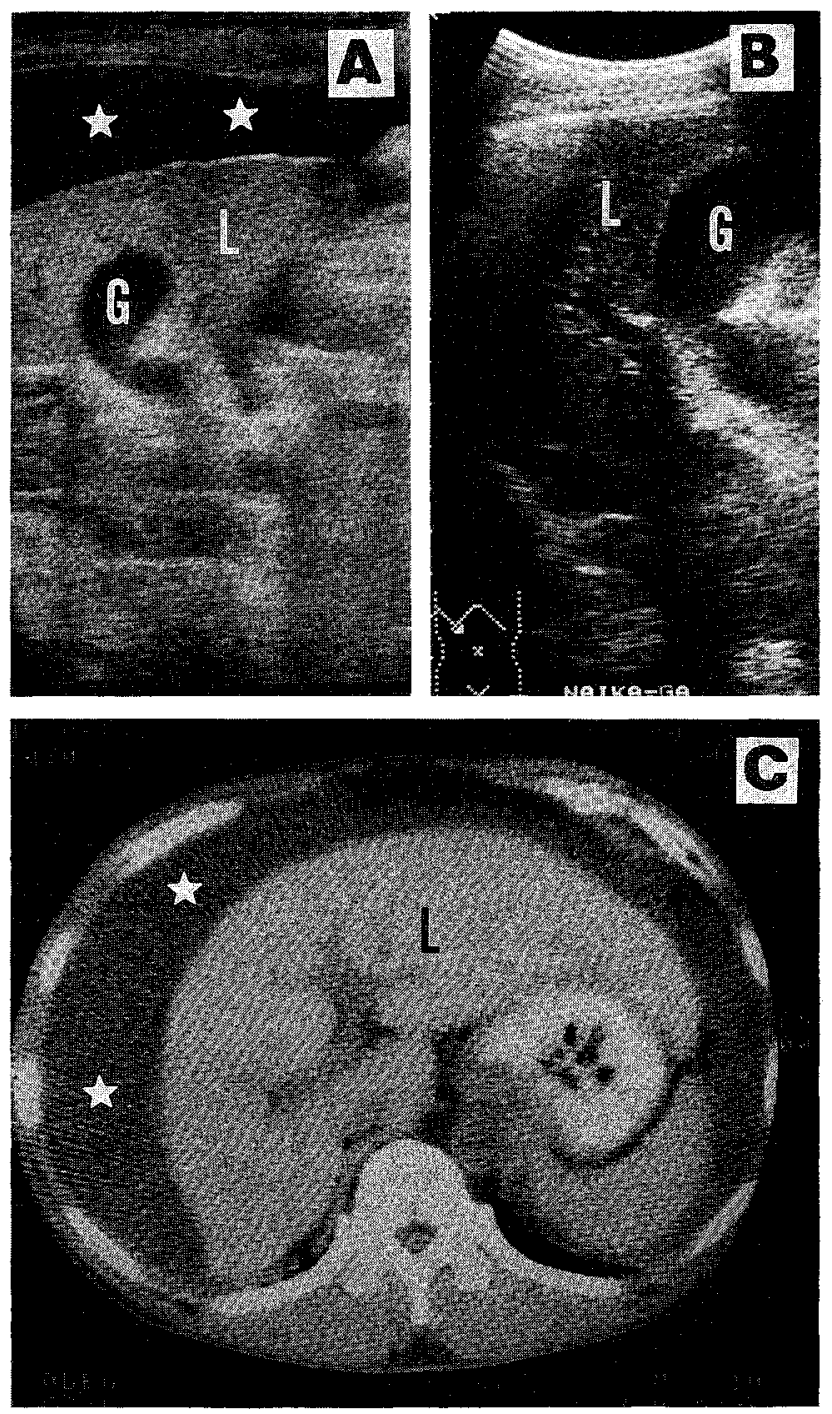

Fig. 2. Abdominal ultrasonogram (A) and computed tomography (C) showing gross ascites, and resolution of ascites after the L-thyroxine (B: ultrasonogram). Star: ascites, L: liver, G: gall bladder. 


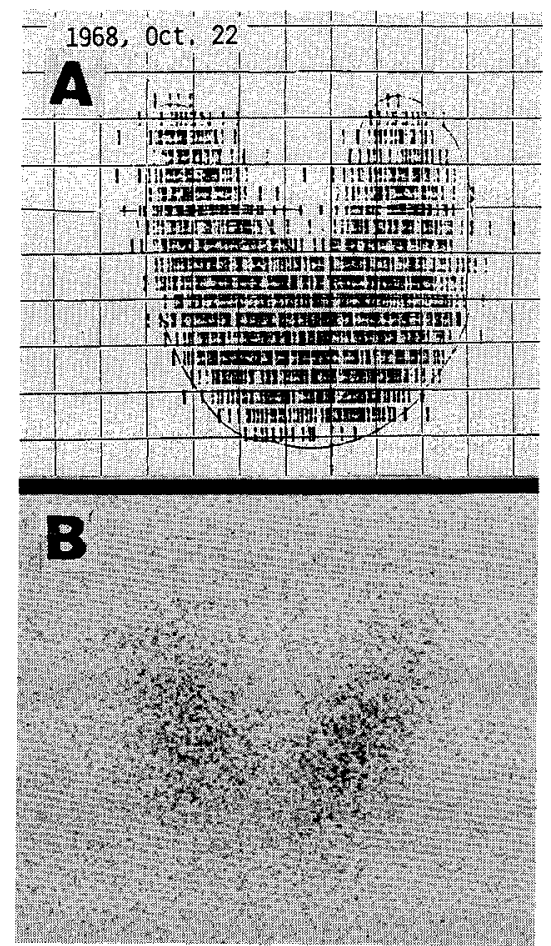

Fig. 3. Radioactive iodine uptake of thyroid gland, A: diffuse uptake of 131 -I $(75.4 \% / 24 \mathrm{~h}$; 1968), B: low diffuse uptake of $123-\mathrm{I}(4.4 \% / 24 \mathrm{~h}$; 1988)

(N, 3.0-5.8) and thyrotropin (TSH) $86.5 \mu \mathrm{U} / \mathrm{ml}(\mathrm{N}, 0.3-$ 4.0). Repeated antithyroglobulin antibodies (TGHA) and microsomalantibodies (MCHA) (hemagglutination technique) were repeatedly negative. TSH bindinginhibiting immunoglobulin (TBII; radioreceptor assay) were negative $(-6.5 \% ; \mathrm{N},<-10)$. Thyroid $123-\mathrm{I}$ uptake was $4.4 \% / 24 \mathrm{~h}$ (N, 10-40) (Fig. 3B). Neck ultrasonographic findings revealed a normal sized thyroid gland without any calcification or mass lesions. The basal metabolic rate was $-25 \%(\mathrm{~N},<-15)$. Thyrotropin releasing hormone stimulation test (TRH; $500 \mu \mathrm{g}$, i.v) resulted in a delayed response in plasma TSH as consistent with primary hypothyroidism (basal $81.3 \mu \mathrm{U} / \mathrm{ml}$ and peak TSH $126 \mu \mathrm{U} / \mathrm{ml}$ at $120 \mathrm{~min}$ ).

The hypothyroidism was treated initially with levothyroxine (L-T4) $25 \mu \mathrm{g} /$ day and gradually increased to $150 \mu \mathrm{g} / \mathrm{day}$. The ascites rapidly disappeared about 1 month after the start of replacement therapy. At that time he was still in a hypothyroid state (free T3 $1.0 \mathrm{pg} / \mathrm{ml}$, free T4 $0.4 \mathrm{ng} / \mathrm{dl}$ and TSH $52.1 \mu \mathrm{U} / \mathrm{ml}$ ). Since then his general condition gradually improved and there was no evidence of any recurrent ascites (Fig. 2B). To date, after $2 \mathrm{yr}$ he appears completely cured, and clinically euthyroid (free T3 $3.2 \mathrm{pg} / \mathrm{ml}$, free T4 $1.4 \mathrm{ng} / \mathrm{dl}$, TSH $0.63 \mu \mathrm{U} / \mathrm{ml}$, TGHA $<100 \times$ and MCHA $<100 \times$ ). The liver function analyses were also within normal limits (GOT 20-26IU/l, GP'T 11-17IU/1, ChE 284 IU/l, prothrombin time $97 \%$, hepaplastin test $103 \%$, ICG at
15 min $6.2 \%$ and $\mathrm{K}$-value 0.184$)$. However, his $99 \mathrm{~m}-\mathrm{Tc}$ liver scan did not change significantly (Fig. 1B).

\section{Discussion}

It is well known in clinical practice that the presentation of hypothyroidism can be very atypical; the classical signs and symptoms may be either absent or very mild, whereas symptoms which appear unrelated to hypothyroidism can distract the physician's attention from the true problem and thus lead to a false diagnosis and to incorrect treatment. Pericardial and pleural effusions are frequenty found in hypothyroidism. The incidence of pericardial effusion in myxedema has been reported to be from 30 to $57 \%(4,5)$. Ascites is, however, a rare complication (1-3). Isolated cases with socalled myxedema ascites has been reported in the absence of cardiac, hepatic or renal failure or other malignant disease have been reported (6-9). Myxedematous effusions are thought to be due to enhanced capillary permeability and the subsequent leakage of proteins into the interstitial space, or a result of hepatic and renal manifestations of hypothyroidism (10). Enhanced interstitial oncotic pressure and an inappropriate secretion of antidiuretic hormone also have been incriminated (11). However, the pathogenesis of ascites in this disease remains obscure.

It has been suggested that myxedema ascites may occur more frequently in patients with autoimmune thyroiditis $(6,9)$. There is an association between Hashimoto's (autoimmune) thyroiditis and autoimmune liver diseases, including lupoid hepatitis and/or primary biliary cirrhosis (12). However, the present patient may have had primary hypothyroidism due to post-treatment of 131-I therapy. During the follow-up studies, there was no evidence suggesting that he had any autoimmune liver disease and/or active autoimmune thyroid disease. Both antithyroidal autoantibodies (TGHA and MCHA) and anti-TSH receptor antibodies were repeatedly negative. The histologic features of the liver in patients with myxedema ascites were described previously to be central fibrosis with replacement of pericentral hepatocytes by connective tissue (13). On the other hand, Clancy and Mackay (6) and others (7) reported that the liver biopsy of similar patients shows normal liver tissue. Furthermore, Robinson (8) reported that significant reversible liver abnormality can occur in such cases after L-thyroxine replacement. The interpretation of these findings is still unclear. Although unetiologic liver damage or chronic hepatitis could not be ruled out in this case, there was no definite evidence suggesting a decompensated state of liver cirrhosis before L-T4 replacement. Moreover, reversible liver dysfunction except for the $99 \mathrm{~m}$-Tc liver scan was also found in the present case as described by Robinson (8). Unfortunately, permission for a liver biopsy was not given by our patient. 


\section{Ascites and Hypothyroidism}

The fluid in patients with myxedema ascites has been described to be yellow and gelatinous, with a high protein content and the specific gravity characteristics of an exudate $(13,14)$. Patients receiving L-thyroxine treatment often exhibit a resolution of ascitic fluid over a period months. In the present case, a rapid disappearance of ascites was observed after L-T4 replacement even before this case attained the clinical euthyroid state. The development of ascites seems to have been an early phenomenon in the progress of hypothyroidism. The prompt response to thyroid replacement confirmed that the hypothyroidism was the cause of the ascites. A careful evaluation of thyroid functions should, therefore, be performed in all patients with unetiological ascites.

\section{References}

1) Sellin $\mathbf{J H}$, Vassilopoulon-Scllin $\mathrm{R}$, Lester $\mathrm{R}$. The gastrointestinal tract and liver. in: Werner's the Thyroid, Ingber SH, Braverman, LE, Eds. J.B. Lippincott Company, Philadelphia, 1986, p 1156.

2) Burgi U, Konig MP. Clinical pathophysiology and metabolic effects of hypothyroidism. Bailliere's Clin Endocrinol Metab 2: $567,1988$.

3) Sachdev Y, Hall R. Effusions into body cavities in hypothyroidism. Lancet 1: 564, 1975.
4) Kerber RE, Sherman B. Echocardiographic evaluation of pericardial effusion in myxedema: Biochemical and clinical correlations. Circulation 52: 823, 1975.

5) Mathew Roy VC, Unnihan RR, Bahulcyan CG. Echocardiographic evaluation of pericardial effusion in hypothyroidism: Incidence, biochemical and therapeutic corrclations. J Assoc Phys India (Bonbay) 34: 111, 1986.

6) Clancy RL, Mackay IR. Myxedematous ascites. Med J Aust 2: $415,1970$.

7) Turner JA, Rapoport J. Myxoedema ascites. Postgrad Med J 53: 343, 1977.

8) Robinson TJ. Ascites associated with gross hypothyroidism. Br J Clin Pract 41: 893, 1987.

9) Kocen RS, Atkinson M. Ascites in hypothyroidism. Lancet 1: $527,1963$.

10) Lange K. Capillary permeability in myxedema. Am J Med Sci 208: 5, 1944.

11) Liechty RL, Miller RF, Cohen WN. Myxedema causing a dynamic ileus, scrous effusions, and inappropriate secretion of antidiuretic hormone. Surg Clin North Am 50: 1087, 1970.

12) Culp KS, Fleming CR, Duffy J, Baldus WP, Dickson ER. Autoimmune association in primary biliary cirrhosis. Mayo Clin Proc 57: $365,1982$.

13) Barker A, Kaplan M, Wolf H. Central congestive fibrosis of the liver in myxedema ascites. Ann Intern Med 77: 927, 1972.

14) Haley HB, Leigh C, Bronsky D, Waldstein SS. Ascites and interstinal obstruction in myxedema. Arch Surg 85: 328, 1965. 